\title{
Learning Lean Six Sigma: A Student Reflective Study
}

\author{
Chad Laux, PhD \\ Email: claux@purdue.edu \\ Ludmila Nunes, PhD \\ Email: nunes@purdue.edu
}

Department of Technology Leadership \& Innovation, Purdue University

Department of Psychological Sciences, Purdue University

\begin{abstract}
Purpose: Lean Six Sigma has become a worldwide effort at continuous improvement. As it becomes more prevalent, the teaching and learning of LSS has not caught up with current trends. The purpose of this paper is to understand how students learn Lean Six Sigma in a classroom environment.

Design/Methodologies/Approach: This paper is based upon teaching students the body of knowledge that aligns with what a Black Belt is expected to know and understand about LSS based upon student self-reflections, utilizing a critical success factor (CSF) framework.

Findings: Students were positive about their own understanding about the body of knowledge and did not demonstrate significant differences when applied to varying project types. While the sample was limited, student focus, through the lens of critical success was focused on design of projects and root cause analyses (Define, Analyze).

Practical Implications: Project based learning (PBL) will continue to be a concept for researchers engaged in the scholarship of learning and teaching (SOTL) in LSS. Developing projects with industry partners adds effort to the instructor but supports authentic learning for the student. The application of LSS for building skills continues to be the most important aspect of LSS understanding.

Originality: This study is unique whereby student reflections of critical thinking is limited in the literature. In addition, CSF's in self-assessment offer a framework for students to understand project and performance.
\end{abstract}

Keywords: Lean Six Sigma, Engineering Technology Education,

Paper Type: Research 


\section{Introduction}

The development of knowledge and skills, and the teaching of students, have been essential to the mission of higher education. HEI's are deeply involved with the practical application of engineering in developing students as future professional practitioners. Students in engineering and technology learn a curriculum that makes practical use of science for improvement of human condition. While the human condition was tightly linked to food production for millennia, the industrial age ushered in societal change that allowed people to improve themselves, without the need for landed resources. The emergence of industry, defined as especially differing from agriculture, has helped power the modern economy (Cabral 2000). However, to utilize these technologies to their fullest capabilities has also required that the ideals of science that produced these technologies also be applied to the operations that harness, manage, and maintain them. For the past 30 years, first the industrial organization, and then other economic sectors have deployed scientific concepts of Lean Six Sigma (LSS) to continuously improve the modern technological systems we have created and organized.

While LSS has matured, and expanded, the teaching and learning, and the scholarship of developing those engineering technology students into professional practitioners has not. In this research study, we focus our attention in the area of scholarship of teaching and learning LSS in HEI's on one area that is deficient: the students themselves. Through operations management concept approach, this study defines and describes, through student qualitative writing how they are learning LSS in a classroom environment, designed to mimic the authenticity of practice through a problem based learning (PBL). The outcomes of this study are a number of propositions from a conceptual framework intended to be offered to future researchers with that the education of LSS in the future focus more on student understanding, as they see it.

\section{Review of the Literature}

The skills, knowledge, experience that the organization possesses is crucial to organizational success of LSS. The importance of LSS upon the modern organization has been demonstrated widely in the literature. Successful adoption of LSS is typically based upon the organization's ability to recoup financial returns of investment by the firm, of which human capital is the most significant driver. LSS efforts are completed as projects by personnel, whereby project performance is based upon successful completion of project goals, typically operationally based, to improve customer satisfaction through reduction of unacceptable variation experienced by the organization's customers (Schroeder et al. 2008). For a LSS program to be measured success, project efforts should add to firm performance. At this level, LSS adoption impact upon firm performance has been documented (Swink \& Jacobs 2012). However, the critical success factors of LSS success is derived by the cumulative effects of project successes (Laureani, Alessandro, Antony 2012). These tactical, or project efforts, should contribute to the organization's strategic success, or firm performance. The relationship between project success and firm performance has been studied in the literature (Kumar et al. 2009). In addition, critical success factors of project success for LSS have been identified (Laux et al. 2014). These factors of success (CSFs) may be summarized through commitment and participation of organizational leadership, project alignment to strategy, project management, an operating framework, utilization of LSS techniques, training of personnel, and project selection (Laux et al. 2014). A relationship of these CSFs are the personnel that drive them. And the development of these professionals is crucial to the continued success of LSS adoption. Professional development of the crucial roles LSS 
practitioners, called Black Belts (full-time LSS project managers), and Green Belts (part-time LSS project managers) are done predominately at the industry level. The educational pathway of LSS professionals starts at the college and university level, though not currently widespread. It is into this opening that this study takes us, that of the scholarship of teaching and learning (SoTL).

The scholarship of teaching and learning (SoTL) involves faculty framing and systematically investigating questions related to student learning, with the goal of improving their own classroom, as well as advancing practice beyond it (CELT, 2017). The goal of SoTL is to improve student learning by methods of research and scholarly inquiry in the learning of students and instructor teaching practices for the ultimate purpose of improving student learning (CELT 2017). This includes the sharing results so others can review, critique and build on the work (CELT 2017). The challenges of the twenty-first century require HEI's to prepare students that are discipline specialists, versed in critical thinking (Kreber, 2007). Thus, scholars recognize that SoTL in their own field is as important as the disciplined based research that the teacher scholar typically conducts. In the area of LSS, SoTL is an emerging, though small area of work.

The scholarship of teaching and learning of LSS in the classroom has predominately been viewed though the instructor. (Antony 2008), in a reflective study of the role of Six Sigma development with regard to higher education institutions describes how many business and engineering schools have not added Six Sigma to their curriculums, despite the fact that Lean and Six Sigma have been adopted by 82 percent of Fortune 100 companies by the 1990's (Noria 1999). (Antony 2008) additionally describes how students of these schools would benefit true value of practically useful quality and process improvement tools which require statistical skills and expertise. LSS has been studied on how to improve delivery of curriculum, though not within the discipline itself in a study of LSS for improving HEI operations (Hess \& Benjamin 2015). In another reflective study, (Hess \& Benjamin 2015) note that the customer focus of LSS aligns well with student focus of HEIs. The major findings, with regards to curriculum delivery, note that LSS could support the idea of student competencies, rather than credit hour, to assess student learning (Hess \& Benjamin 2015). However, there are a few studies with regard to SoTL and the LSS discipline.

In a comparative study of two courses where author compared the teaching effectiveness between two courses from two different universities of Industrial Engineering undergraduates and graduate students learning Six Sigma (Furterer 2007). The focus of the paper was an assessment of instructional strategies based upon student survey, direct instructor observation, and teaching evaluations. Students applied material learned in both classes to an industry project. Results demonstrated that real-world experiential learning was a valuable way for students to learn including the Six Sigma tools and the DMAIC problem solving approach, though more effective for graduate students (Furterer 2007). Finally, (Furterer 2007) notes that due to constraints, it was difficult for the instructor to serve as project mentor and classroom instructor, a crucial aspect of learning Six Sigma. In another SoTL study, (Leduc et al. 2010) describe how LSS is taught in an undergraduate capstone course that included student-industry projects, in addition to classroom delivery. Results of the study were that students did not complete projects on par with professionals, but that the students were likely to be ahead of peers in the area of process improvement (Leduc et al. 2010). Finally, in a study by (Zhan \& Porter 2008), the authors discuss teaching Six Sigma as a course project in an undergraduate Electrical 
Engineering Technology (EET) course (Zhan \& Porter 2008). The authors adopted LSS DMAIC (Define, Measure, Analyze, Improve, Control) methodology to an existing EET design project. In a student survey and teaching evaluation of the study results, students were positive about learning Six Sigma, though they noted the need for project examples to help understand the curriculum (Zhan \& Porter 2008). In review of these efforts, the authors note that there has been little SoTL work in LSS. In addition, these studies have included two major components in instruction: the traditional lecture and some project based leaning. In the current study of this paper, these components are a foundation for teaching graduate students LSS.

\section{Methods}

This paper is based upon teaching graduate students the body of knowledge that aligns with what a Black Belt is expected to know and understand with regard to LSS. The course is offered over two semesters to extend the amount of time needed to learn and apply the DMAIC methodology. The course objectives were designed with the understanding of the difficulty of standardizing on the Six Sigma body of knowledge (Antony 2008). To mitigate this content variation and to standardize, the course outcomes were developed off of two professional and academic associations' body of knowledge: the Association of Technology Management and Applied Engineering (ATMAE), and the International Organization for Standards (ISO) body of knowledge, in addition to the instructor's own subject matter expertise, who holds multiple Black Belt certifications.

\subsection{Course and Sample}

This course is taught in a large Midwestern University. The course design followed a reverse curriculum model, designed to start with a curriculum design process that begins the purpose of the task or the desired results and works backward from there (Wiggins, G. McTighe 2005). In addition, understanding is explored through multiple facets, including perspective, empathy, and self-knowledge, rather than just the conventional explanation, interpretation, and application (Wiggins, G. McTighe 2005). Based upon this idea, the course is largely based upon application, perspective, and self-knowledge through student-organization projects, active learning in the classroom, rather than lecture delivery, and student reflections. Students admitted to the course are both graduate (7) and undergraduate students (2) where prior knowledge of statistics are required and admitted upon instructor approval and therefore there shouldn't be major differences between the learning process in the context of this course. There were seven students in this initial course offering involved in this study. The course content is based upon a webbased delivery of the curriculum. At the end of the second semester, students are issued an internal Black Belt certificate of completion, and if students complete the project, are issued a Black Belt certificate. The issue of certifications has come up in the literature, (Gore 2004), certification has a long tradition in higher education as an educational milestone. The culmination of that certificate issue is a project conducted with an outside organization. Based upon the principles of project based learning (PBL), the comprehensive effort is designed to engage students in investigation of authentic problems (Blumenfeld et al. 1991). Based upon (Blumenfeld et al. 1991) model, there are two important project components: the project requires a question or problem to serve the organization and drive project activities. The DMAIC project that the students conduct is based upon project objectives, strategic case, problem statement to define project parameters. Second, the project activities result in a series of artifacts, in this study milestone completions, that result in a final product (Blumenfeld et al. 1991). In the class, 
students are responsible for both.

\subsection{Measures}

Students' perceptions about learning LSS in the classroom using a PBL methodology were assessed by requesting students to write short reflections about different aspects of their experience. These written assignments were requested throughout the semester at four different time points, to assess the development of perceptions during the project execution. Students were encouraged to be specific in their comments, allowing us to analyze how students perceive their own accomplishments, based upon this reflection model, derived from CSFs of: a) leadership commitment and participation, project alignment to business strategy, SS framework, project management/execution, utilization of SS tools, SS training, and project selection (Laux et al. 2015).

\section{Results}

Student responses were coded as: positive, negative, or neutral based upon their reflection, per assignment, per student team. There were two student teams of both graduate and undergraduate students. One team project was based upon improving a food manufacturing process. The other student team focused on improving grant proposal processing at an HEI. Table 2 below shows that most student responses were positive with little difference between the two project types.

Table 1. Frequency Counts of Student Reflection Per CSF Framework

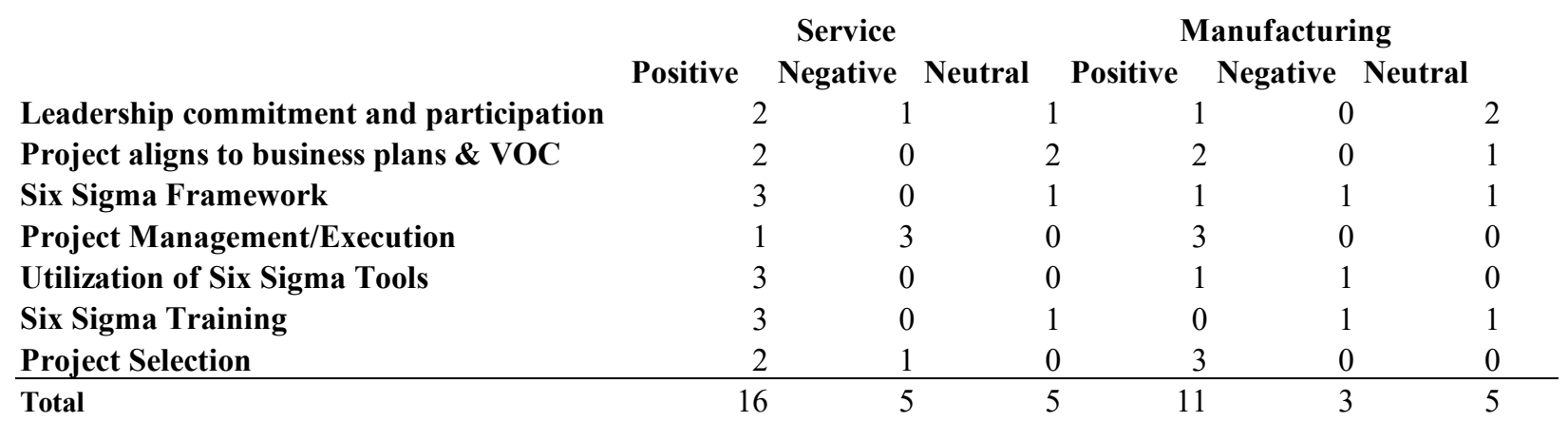

Next, responses were coded by learning objectives. Those objectives, with regard to these 4 assignments, were:) design a Lean Six Sigma effort through project definition elements; 2) synthesize a process and a processes supply chain elements; 3 ) create a visualization of a process through flow, precedence, activities, and information and analyze the value by the Seven Lean 'wastes' of this 'business process map'; 4) analyze the customer's voice to identify key issues and create requirements of process performance; 5) create a measure for meaning strategy for a LSS effort; 6) conduct root cause analysis in a problem based approach; 7) understand failure modes and how to calculate risk of changes to a process; 8) understand how to create a contingency plan for process quality assurance; and 9) comprehend the importance of translating LSS project efforts into a viable form through synthesis of artifacts into a understandable form of presentation. Table 2 below shows the frequency counts per learning objective.

Table 2. Frequency Counts of Student Reflection Per Learning Objective 


\begin{tabular}{lrrrrrr} 
& \multicolumn{2}{c}{ Service } & \multicolumn{3}{c}{ Manufacturing } \\
& Positive & Negative & Neutral & Positive & Negative & Neutral \\
\hline LO1 & 12 & 2 & 2 & 4 & 1 & 1 \\
LO2 & 3 & 0 & 0 & 0 & 0 & 0 \\
LO3 & 4 & 1 & 0 & 0 & 0 & 0 \\
LO4 & 6 & 1 & 2 & 0 & 0 & 1 \\
LO5 & 2 & 0 & 0 & 2 & 0 & 0 \\
LO6 & 5 & 0 & 0 & 0 & 0 & 1 \\
LO7 & 2 & 0 & 0 & 0 & 0 & 0 \\
LO8 & 1 & 0 & 0 & 0 & 0 & 0 \\
LO9 & 1 & 0 & 1 & 1 & 0 & 0 \\
\hline Total & 36 & 4 & 5 & 7 & 1 & 3
\end{tabular}

The use of significance testing throughout this study was precluded due to limited sample size. Yet, table 2 above shows that there was much more student critical thinking with regard to the service than manufacturing project, predominantly in the with regard to project design (LO1). In review of the details, students noted the difficulty of conducting a LSS project in service, in an HEI setting. Finally, a comparison of CSF's and LO's was done to identify relationships among these course features as shown in table 3 below.

Table 3. Frequency Counts of Student Reflection Per Learning Objective

\begin{tabular}{lrrrrrrrrrr|r} 
& LO1 LO2 & LO3 & LO4 & LO5 & LO6 & LO7 & LO8 & LO9 & Total \\
Leadership commitment and participation & 2 & 0 & 0 & 1 & 0 & 1 & 0 & 1 & 0 & 5 \\
Project aligns to business plans \& VOC & 6 & 0 & 0 & 3 & 0 & 0 & 0 & 0 & 0 & 9 \\
Six Sigma Framework & 4 & 0 & 0 & 1 & 0 & 1 & 0 & 0 & 2 & 8 \\
Project Management/Execution & 1 & 0 & 0 & 0 & 2 & 0 & 0 & 0 & 0 & 3 \\
Utilization of Six Sigma Tools & 2 & 1 & 2 & 2 & 1 & 3 & 1 & 0 & 0 & 12 \\
Six Sigma Training & 2 & 2 & 2 & 1 & 1 & 1 & 1 & 0 & 1 & 11 \\
Project Selection & 4 & 0 & 1 & 2 & 0 & 0 & 0 & 0 & 0 & 7 \\
\hline Total & 21 & 3 & 5 & 10 & 4 & 6 & 2 & 1 & 3 &
\end{tabular}

Utilizing the CSF framework, students did not reflect their understanding of LSS, through the lens of project based learning, that related to all learning objectives. In fact, a few LO's $(1,4,6)$ much more often than others. These LO's related to project design and root cause analysis, but little else. However, viewed from a CSF perspective, students primarily reflected upon their own training (learning) and utilization (skills building) of LSS.

\section{Conclusions}

This study was conducted on a LSS Black Belt course for both graduate and undergraduate students that learned through a project based learning approach. The course was designed for students to apply their understanding to external projects and reflect upon their own learning. Results show that students were positive with their own understanding with no clear distinction between the types of projects, though, caution should be noted due to the limited responses given and that the student reflections have not completed, at the time this study was published, all the 
requisite DMAIC steps. However, students focused their attention upon design with regard to projects and their own skill building with regard to themselves. This study was limited by the size of the sample and caution should be taken in generalizing to a wider degree. Nevertheless, to our understanding, the use of student reflections in LSS SoTL is novel and presents a potential research approach for future understanding in this field. In addition, while CSF is a key concept in LSS, the use of CSF's as self-assessment may also present an avenue. The learning of LSS has been described as teaching a problem based approach requiring a rich context. Utilizing the students own critical thinking could help scholars draw out a thick description that is more reflective of LSS efforts.

\section{References}

Antony, J., 2012. A SWOT analysis on Six Sigma: some perspectives from leading academics and practitioners. International Journal of Productivity and Performance Management, 61(6), pp.691-698. Available at: http://www.emeraldinsight.com/10.1108/17410401211249229 [Accessed July 29, 2014].

Antony, J., 2008. What is the role of academic institutions for the future development of Six Sigma? International Journal of Productivity and Performance Management, 57(1), pp.107-110.

Blumenfeld, P. et al., 1991. Motivating Project-Based Learning: Sustaining the Doing, Supporting the Learning. Educational Psychologist, 26(3 \& 4), pp.369-398.

Cabral, L.M.B., 2000. What Is Industrial Organization? Introduction to Industrial Organization. CELT, 2017. Scholarship of Teaching and Learning (SoTL) Scholars Program - CELT. Iowa State Center for Excellence in Learning and Teaching. Available at:

http://www.celt.iastate.edu/faculty/programs/scholarship-of-teaching-and-learning-sotl-scholarsprogram [Accessed March 15, 2017].

Furterer, S., 2007. INSTRUCTIONAL STRATEGIES AND TOOLS TO TEACH SIX SIGMA TO ENGINEERING TECHNOLOGY UNDERGRADUATE STUDENTS Instructional Strategies and Tools to Teach Six Sigma to Engineering Technology Undergraduate Students. In Proceedings of the American Society for Engineering Education Conference.

Gore, D.W., 2004. Is Six-Sigma Certification Appropriate for the Classroom? In Proceedings of the American Society for Engineering Education Conference.

Hess, J.D. \& Benjamin, B.A., 2015. Applying Lean Six Sigma within the university: opportunities for process improvement and cultural change. International Journal of Lean Six Sigma, 6(3), pp.249-262. Available at: http://dx.doi.org/10.1108/IJLSS-12-2014-0036.

Kreber, C., 2007. What's it really all about? The Scholarship of Teaching and Learning as an Authentic Practice. International Journal for the Scholarship of Teaching and Learning, 1(1), pp.1-4. Available at: http://academics.georgiasouthern.edu/ijsotl/v1n1/essays/kreber/IJ_Kreber.pdf.

Kumar, M., Antony, J. \& Cho, B.R., 2009. Project selection and its impact on the successful 
deployment of Six Sigma. Business Process Management Journal, 15(5), pp.669-686. Available at: http://www.emeraldinsight.com/10.1108/14637150910987900 [Accessed July 18, 2014].

Laureani, Alessandro, Antony, J., 2012. CSFs of effection LSS implementation.pdf.

International Journal of Lean Six Sigma, 3(4), pp.274-283.

Laux, C., Johnson, M. \& Cada, P., 2014. Project barriers to Green Belts through critical success factors. International Journal of Lean Six Sigma, Vol. 6 No.(No. 2), pp.138-160.

Laux, C., Johnson, M. \& Cada, P., 2015. Project barriers to Green Belts through critical success factors. International Journal of Lean Six Sigma, 6(2), pp.138-160. Available at:

http://dx.doi.org/10.1108/IJLSS-02-2014-0006.

Leduc, A., Hadley, G. \& Ratzlaff, M., 2010. Immersive learning using Lean Six Sigma methodology in the Manufacturing Engineering Technology capstone course. ASEE Annual Conference and Exposition, Conference Proceedings. Available at: http://www.scopus.com/inward/record.url?eid=2-s2.0-77955933372\&partnerID=tZOtx3y1.

Noria, 1999. Report finds Six Sigma has saved Fortune 500 \$427B. Reliable Plant. Available at: http://www.reliableplant.com/Read/4285/report-finds-six-sigma-has-saved-fortune-500$\% 24427 b$ [Accessed March 16, 2017].

Schroeder, R.G. et al., 2008. Six Sigma: Definition and underlying theory. Journal of Operations Management, 26(4), pp.536-554. Available at: http://linkinghub.elsevier.com/retrieve/pii/S0272696307000897 [Accessed July 11, 2014].

Swink, M. \& Jacobs, B.W., 2012. Six Sigma adoption: Operating performance impacts and contextual drivers of success. Journal of Operations Management, 30(6), pp.437-453. Available at: http://dx.doi.org/10.1016/j.jom.2012.05.001.

Wiggins, G. McTighe, J., 2005. Understanding by design., Ascd. Vancouver.

Zhan, W. \& Porter, J., 2008. TEACHING SIX SIGMA IN A COURSE PROJECT Teaching Six Sigma in a Course Project. In Proceedings of the American Society for Engineering Education Conference. 